Original article

\title{
Sensitivity to criticism and praise predicts schizotypy in the non-clinical population: The role of affect and perceived expressed emotion
}

\author{
Preethi Premkumar ${ }^{\mathrm{a}, *}$, Andrew K. Dunn ${ }^{\mathrm{a}}$, Juliana Onwumere ${ }^{\mathrm{b}, \mathrm{c}, 1}$, Elizabeth Kuipers ${ }^{\mathrm{b}, \mathrm{c}, 1}$ \\ a Department of Psychology, School of Social Sciences, Nottingham Trent University, Nottingham, UK \\ b King's College London, Department of Psychology, Institute of Psychiatry, Psychology and Neuroscience, London, UK \\ ${ }^{\mathrm{c}}$ NIHR Biomedical Research Centre for Mental Health, South London and Maudsley NHS Foundation Trust, London, UK
}

\section{A R T I C L E I N F O}

\section{Article history:}

Received 10 September 2018

Received in revised form 29 October 2018

Accepted 29 October 2018

Available online 21 November 2018

Keywords:

Schizotypy

Expressed emotion

Criticism

Depression

Mood

Praise

\begin{abstract}
A B S T R A C T
Background: Schizotypy represents a cluster of personality traits consisting of magical beliefs, perceptual aberrations, disorganisation, and anhedonia. Schizotypy denotes a vulnerability for psychosis, one reason being psychosocial stress. High expressed emotion (EE), a rating of high criticism, hostility, and emotional over-involvement from a close relative, denotes psychosocial stress and vulnerability to psychosis, and is associated with schizotypy. This study aimed to decipher the relationship of schizotypy to perceived criticism and perceived praise in terms of affect and perceived EE.

Methods: Ninety-eight healthy participants listened to short audio-clips containing criticism, praise, and neutral comments from a stranger, and evaluated them in terms of the comments' arousal and personal relevance. Participants also answered self-report questionnaires of schizotypy, depression, mood, and perceived EE. Correlational analyses tested the relationship between schizotypy and the evaluations of criticism and praise. Mediation analyses then tested whether depression, positive mood, and perceived EE explained these relationships.

Results: Greater relevance of standard criticism correlated with higher positive schizotypy. This association was fully mediated by high depression and perceived irritability from a close relative. Lower relevance of standard praise correlated with higher cognitive disorganisation (another schizotypal trait). This relationship was partially mediated by low positive mood and high perceived intrusiveness from a close relative.

Conclusion: Greater perceived criticism and lower perceived praise predict schizotypy in the healthy population. Affect and interpersonal sensitivity towards a close relative explain these relationships, such that depression increases perceived criticism, and positive mood increases perceived praise. Perceived EE defines the interpersonal nature of schizotypy.
\end{abstract}

Crown Copyright @ 2018 Published by Elsevier Masson SAS. All rights reserved.

\section{Introduction}

Negative family communication is a risk factor for the onset and relapse of psychosis. Expressed Emotion (EE) measures both positive and negative aspects of relationships. High EE is rated

\footnotetext{
* Corresponding author at: Department of Psychology, Nottingham Trent University, 50 Shakespeare Street, Nottingham, NG1 4FQ, UK.

E-mail address: Preethi.premkumar@ntu.ac.uk (P. Premkumar).

${ }^{1}$ For authors JO \& EK this paper represents independent research [part] funded by the National Institute for Health Research (NIHR) Biomedical Research Centre at South London and Maudsley NHS Foundation Trust and King's College London. The views expressed are those of JO \& EK and not necessarily those of the NHS, the NIHR or the Department of Health.
}

when a close relative expresses high levels of criticism, hostility or intrusive overconcern - emotional overinvolvment (EOI). Patients with psychosis can experience high expressed emotion (EE) in a family environment [1], and can then more likely experience a psychotic relapse [2]. High EE also relates to more distress in people with psychosis-like experiences [3] and to schizotypal personality traits in the non-clinical population [4]. Schizotypy is a set of latent personality traits in the healthy population that reflect a putative risk for psychosis [5].

\subsection{Schizotypy and its relationship with perceived criticism}

Positive schizotypy is a dimension of schizotypal personality that constitutes spiritual beliefs, paranormal beliefs, delusions, and 
hallucinations [6]. It can relate to perceived criticism if criticism is socially threatening and if the social threat is attributed to spiritual and paranormal beliefs $[7,8]$. Perceived criticism denotes social threat, as people with social anxiety disorder are sensitive to their partner's criticism [9]. Experiencing social threat can encourage spiritual and paranormal beliefs typical of positive schizotypy in people with certain religious beliefs in the non-clinical population $[7,10]$.

Affect plays a role in the emergence of psychosis-like experiences [11]. Depression related more strongly to positive schizotypy than negative schizotypy in a large college sample $(n=1,258)$ [12]. Depression relates to perceived criticism in people with positive schizotypy within the non-clinical population [4]. Depression could relate to perceived criticism because it increases maladaptive metacognitive beliefs about social threat, such as the person believing that criticism is uncontrollable and dangerous, and believing that one needs to worry to gain control over a situation [13,14]. The relationship between depression and perceived criticism deepens if adolescents with depression find their parents irritable [15].

\subsection{Schizotypy and its relationship with perceived praise}

Another explanation for the relation between high EE and psychosis-like experiences is a decrement in praise. Young children who access mental health services are three times less likely to be praised than criticised by their parents [16]. Cognitive disorganisation is a schizotypal trait characterised by social anxiety, moodiness, difficulty maintaining attention, and difficulty making decisions [6]. In people in the non-clinical population with schizotypal traits, greater disorganisation relates to greater acceptance of unfair social rewards, indicating that schizotypy is associated with poor evaluation of social reward [17]. Cognitive disorganisation could relate to less perceived praise if patients with psychosis and cognitive disorganisation are less selfcompassionate [18]. Thought disorder relates to a lower need among patients with schizophrenia for others' approval, and a poor clarity of expression from their mothers $[19,20]$. Thought disorder is a severe form of cognitive disorganisation, characterised by illogical thinking, loose association, and peculiar language [21,22]. A carer expressing more praise reduces disorganisation in adolescents who are at risk for psychosis [23].

In contrast, excessive warmth from a close relative due to EOI relates to more anxiety across the psychosis continuum [24-26]. EOI consists of parents being overprotective, intrusive, and controlling [1]. EOI could inhibit the child's autonomy and competence [27], and diminish the child's ability to describe their emotions, such as perceiving praise [28]. Meanwhile, positive affect could improve perceived praise, because positive mood broadens one's attention and encourages positive thoughts about engaging in pleasurable social activities [29]. Maternal praise deepens positive mood [30].

\subsection{Study aims and hypotheses}

High levels of EE in carers can relate to poor outcomes in patients with psychosis [2] and influence the propensity for schizotypal experiences in the healthy population [4]. According to the stress diathesis hypothesis of schizophrenia [31], stressors, such as persistent social environmental stress, interact with a preexisting vulnerability for psychosis and lead to psychotic episodes. The current study aimed to determine whether affect and perceived EE could explain the relationship of schizotypy to perceived criticism and perceived praise in the general population, because EE could be perceived as threatening even in the normal range of the psychosis continuum, and so increase vulnerability for psychosis. It was hypothesised that (1) greater perceived criticism would relate to greater positive schizotypy, (2) greater perceived praise would relate to lower cognitive disorganisation, (3) depression and perceived EE would mediate the relationship between perceived criticism and positive schizotypy, and (4) positive mood and perceived EE would mediate the relationship between perceived praise and cognitive disorganisation.

\section{Method}

\subsection{Participants}

Ninety-eight participants completed the study. The participants were University psychology students (90\%) recruited in exchange for psychology research credits, and people from the wider public recruited through opportunistic sampling. The participants needed to have a close relative, that is a parent, sibling, or partner, with whom they were in contact for at least $10 \mathrm{~h}$ a week, either face-toface or by speaking to them on the phone. This criterion was applied so that participants could perform the task of evaluating standard criticism and standard praise by referring to their close relative. Participants below 18 years and above 50 years were excluded, so that the sample represented people in early- to midadulthood. The participants were 22.6 years old on average (S. D. $=5.69$, range 18 to 46 years, $82 \%$ were 25 years or below) and predominantly female (81\%). Eighty percent of participants was single, $15 \%$ was cohabiting, and $5 \%$ was married. In terms of ethnicity, 68\% was Caucasian, $24 \%$ was Asian, and $8 \%$ was of African-Caribbean heritage.

\subsection{Psychometric assessments}

\subsubsection{Oxford-Liverpool inventory of feelings and experiences (O-LIFE)} [6]

The participants rated the 104 O-LIFE items on a 2-point scale (Yes/No). The scale has four subscales, namely unusual experiences (positive schizotypy), cognitive disorganisation (social anxiety, moodiness, and lack of concentration), introvertive anhedonia (withdrawal and lack of pleasure in physical and social sources), and impulsive non-conformity (aggression and lack of self-control). Impulsive non-conformity is less relevant to the schizotypal organisation compared to other subscales [32], and so was not included in subsequent analyses. The subscales have good internal reliability (Cronbach's alpha, $\alpha$ ) in the current sample: unusual experiences $_{\alpha}=0.89$, cognitive disorganisation ${ }_{\alpha}=0.89$, introvertive anhedonia $_{\alpha}=0.78$, impulsive non-conformity $y_{\alpha}=0.70$.

\subsubsection{Depression, anxiety, and stress scale (short form, DASS-21) [33]}

The scale has 21 items of which 7 items measured depression and 7 measured anxiety. Participants rated the items by referring to their past week. The items were rated on a 4-point Likert scale. The subscales have good internal reliability in the current sample $(\alpha=0.86)$.

\subsubsection{Level of expressed emotion scale (LEE) [34,35]}

The 38-item version of the LEE scale measures a person's perception of EE in their close relative over the last three months. The scale measures lack of emotional support, intrusiveness, irritability, and criticism. The participants rated the items on a 4point Likert scale. The subscales have good to excellent internal reliability in the current sample as follows, lack of emotional support $_{\alpha}=0.93$, intrusiveness $s_{\alpha}=0.82$, irritability ${ }_{\alpha}=0.80$, and criticism $_{\alpha}=0.75$.

\subsubsection{Perceived criticism scale [36]}

This is a single-item question. It asks the individual, 'How critical is your spouse/relative of you?' It is rated on a 10-point 
Likert scale [36]. A higher rating of perceived criticism relates to more EE-criticism from a carer in patients with psychosis; however, the measure is less predictive of patient psychopathology than directly rated EE-criticism [37,38].

\subsubsection{Positive and negative affect scale (PANAS) [39]}

This scale has 10 positive mood descriptors denoting a state of high energy, full concentration, and pleasurable engagement, and 10 negative mood descriptors denoting aversive mood. Participants indicated how much they currently felt about each descriptor on a 5-point Likert scale. The internal reliability of positive $\operatorname{mood}_{\alpha}$ was 0.91 , and that of negative $\operatorname{mood}_{\alpha}$ was 0.86 in the current sample.

\subsection{Affective evaluation of standard criticism and standard praise}

The participants listened to 40 standard criticisms, 40 standard praises, and 40 standard neutral comments, and evaluated the arousal and personal relevance of the comments by referring to their close relative. These comments had been developed in an earlier study [40]. The criticisms followed the conventions of rating the Camberwell Family Interview of a close relative (the gold standard measure for rating EE) for EE-criticism which is defined as 'a statement which, by the manner in which it is expressed, constitutes an unfavourable comment upon the behaviour or personality of the person to whom it refers' [1, p. 38]. Likewise, praise was developed following the conventions of rating the Camberwell Family Interview for EE-positive comments which is defined as a statement that expresses 'praise, approval or appreciation of the behaviour or personality of the person to whom it refers' [1, p. 62-63]. Neutral comments were scientific facts and comments on the weather. Comments were spoken in a male or female voice. The speakers were postgraduate Psychology students who had a similar age and level of education. The speakers were trained to emphasise different emotional reactions in their tone and pitch just as when a close relative evokes criticism and positive comments. Criticism lasted longer when spoken in a female voice $[$ mean $($ S.D. $)=8.2 \mathrm{~s}(0.72)]$ than a male voice $[$ mean $(\mathrm{S}$. D. $)=6.1 \mathrm{~s}(0.44)], \mathrm{F}(1,38)=456.5, \mathrm{p}<0.001$. Praise lasted longer when spoken in a female voice [mean (S.D.) $=6.8 \mathrm{~s}(1.3)$ ] than a male voice [mean (S.D.) $=6.4 \mathrm{~s}(0.80)$ ], $\mathrm{F}(1,38)=3.9, \mathrm{p}=0.05$. Neutral comments lasted longer when spoken in a female voice $[$ mean (S.D.) $=9.7 \mathrm{~s}(1.2)]$ than a male voice $[$ mean (S.D.) $=7.9 \mathrm{~s}$ (1.0)], $\mathrm{F}(1,38)=244.7, \mathrm{p}=0.05$.

\subsection{Procedure}

Participants were administered the task individually in a Psychology research lab. The participants rated their current mood before performing the evaluation task. Participants were told that they would listen to auditory remarks comprising criticisms, praise, and neutral comments. The emotional comments would be the kind of comments the participant would hear day-to-day in conversation with their close relative. On listening to each comment, participants were asked to answer how arousing (i.e. emotionally demanding) the comment was, and how relevant the comment was in terms of their own close relationships. Then, they listened to the comments through a pair of headphones (Sennheiser HD-205) and scored them on arousal ('How arousing was this comment?') and personal relevance ('How relevant was this comment?') on 11-point Likert scales. The task was delivered on a computer using Opensesame (version 0.27.2) [41]. The task took approximately $20 \mathrm{~min}$. At the end, participants completed an online survey (Google forms) containing the abovementioned scales. The study received ethical approval from the University's School of Social Sciences Research Ethics Committee (No. 2013/27).

\subsection{Statistical analysis}

The median arousal and median relevance of the 40 comments in each condition (criticism, praise, and neutral comments) were calculated. Analyses of variance compared the three conditions on the median arousal and median relevance of the comments. Twotailed Pearson correlations were performed between the evaluations of criticism and praise (median arousal and median relevance) on the one hand, and scores of schizotypy, depression, anxiety, positive mood, and negative mood, Perceived Criticism Scale, and LEE, on the other hand. A mediation analysis was performed with relevance of criticism as the predictor variable, positive schizotypy (O-LIFE unusual experiences) as the outcome variable, and LEE-irritability and depression as the mediators. Five thousand bootstrap samples were applied. A second mediation analysis was performed with the relevance of praise as the predictor variable, cognitive disorganisation as the outcome variable, and LEE-intrusiveness and positive mood as mediators. Statistical analyses were performed in SPSS (version 24) and the PROCESS macro in SPSS [42].

\section{Results}

\subsection{Participant characteristics}

Twelve participants (12\%) had high positive schizotypy based on a score $\geq 18$ on the O-LIFE unusual experiences subscale [43]. Seventy-one percent of the sample had normal to mild depression, $15 \%$ had moderate depression and 14\% had severe depression [33]. Fifty-three percent had normal to mild anxiety, 19\% had moderate anxiety and $28 \%$ had severe anxiety.

\subsection{Evaluations of criticism and praise}

There was a main effect of emotion on arousal, $F$ (1.78, 173.14) $=281.59, p<0.001$ (the Greenhouse-Geisser method of correcting the violation of the sphericity assumption was applied). Bonferroni-corrected post hoc tests showed that praise was more arousing than criticism [mean difference (standard error of mean, S.E.M. $=1.03(0.26), p<0.001$ ], and more arousing than neutral comments [mean difference (S.E.M.) $=5.66(0.21), p<0.001$ ] Criticism was more arousing than neutral comments [mean difference (S.E.M.) $=4.63(0.29), p<0.001$ ]

There was a main effect of emotion on relevance, $F$ (1.74, $168.82)=216.08, p<0.001$. Praise was more relevant than criticism [mean difference (S.E.M.) $=1.00$ (0.29), $p<0.001$ ], and more arousing than neutral comments [mean difference (S.E.M.) $=5.06$ (0.20), $p<0.001]$. Criticism was more relevant than neutral comments [mean difference (S.E.M.) $=4.06(0.27), p<0.001$ ]

\subsection{Correlation of evaluation of criticism and praise against schizotypy, perceived EE and mood}

The relevance of criticism correlated positively with several schizotypal subscales, namely unusual experiences (positive schizotypy), cognitive disorganisation, and introvertive anhedonia, and with depression, negative mood, perceived criticism LEEirritability, and LEE-criticism. The arousal from criticism correlated positively with cognitive disorganisation, LEE-irritability, and LEEcriticism (Table 1). The relevance of praise correlated negatively with the schizotypal traits of cognitive disorganisation and introvertive anhedonia, and LEE-intrusiveness, and positively with positive mood. The arousal from praise correlated positively with positive mood and negative mood. 
Table 1

Mean (standard deviation) and zero-order correlations between arousal and relevance of criticism and praise, and schizotypy, depression, perceived criticism, level of expressed emotion, and mood.

\begin{tabular}{llllll}
\hline & Mean (S.D.) & 1 & 2 & 3 & 4 \\
\hline 1. Criticism arousal & $5.71(2.53)$ & 1 & & & \\
2. Criticism relevance & $4.82(2.57)$ & $0.503^{*}$ & 1 & & \\
3. PC arousal & $6.73(1.92)$ & $0.366^{* * *}$ & 0.162 & 1 & \\
4. PC relevance & $5.81(2.10)$ & 0.015 & $0.249^{*}$ & $0.475^{* * *}$ & 1 \\
5. OLIFE - UE & $8.92(6.46)$ & 0.068 & $0.274^{* *}$ & 0.010 & 0.054 \\
6. OLIFE - CD & $13.45(6.15)$ & $0.335^{* * *}$ & $0.429^{* * *}$ & 0.165 & $-0.244^{*}$ \\
7. OLIFE - IA & $7.31(4.49)$ & 0.118 & $0.236^{*}$ & 0.089 & $-0.208^{*}$ \\
8. Depression & $10.20(9.10)$ & 0.165 & $0.394^{* * *}$ & 0.123 & -0.172 \\
9. Anxiety & $11.51(9.81)$ & 0.134 & $0.274^{* *}$ & 0.081 & -0.161 \\
10. PANAS - positive & $29.63(8.25)$ & -0.036 & -0.006 & $0.244^{*}$ & $0.488^{* * *}$ \\
11. PANAS - negative & $13.35(4.46)$ & 0.184 & $0.247^{*}$ & $0.254^{*}$ & 0.134 \\
12. PCS & $5.45(2.78)$ & 0.125 & $0.228^{*}$ & 0.097 & -0.030 \\
13. LEE - LES & $63.17(9.17)$ & 0.158 & 0.186 & -0.011 & -0.168 \\
14. LEE - Intrusiveness & $21.26(5.31)$ & 0.153 & 0.125 & -0.050 & $-0.204^{*}$ \\
15. LEE - Irritability & $18.40(3.71)$ & $0.266^{* *}$ & $0.296^{* *}$ & 0.140 & 0.031 \\
16. LEE - Criticism & $15.67(3.09)$ & $0.218^{*}$ & $0.232^{*}$ & 0.040 & -0.197 \\
\hline
\end{tabular}

Footnote: The correlation is significant at ${ }^{*} \mathrm{p}<0.05,{ }^{* *} \mathrm{p}<0.01$, and ${ }^{* * *} \mathrm{p}<0.001 ; \mathrm{CD}$ : cognitive disorganisation, IA: introvertive anhedonia, LEE: Level of Expressed Emotion, LES: lack of emotional support, NC: neutral comments, O-LIFE: Oxford and Liverpool Inventory of Feelings and Experiences, PANAS: Positive and Negative Affect Scale, PC: positive comments, PCS: perceived criticism scale, UE: unusual experiences.

\subsection{Mediators of the relationship between schizotypy and the relevance of criticism and praise}

The first mediation analysis revealed that the relevance of criticism had a significant total effect on positive schizotypy (without the mediators, Table 2). After including the mediators (depression and LEE-irritability), the direct effect of relevance of criticism on positive schizotypy was non-significant. Fig. 1 shows that the relation between the relevance of criticism and positive schizotypy was strongest when either depression or LEE-irritability were high ('moderate mediators', 5\% variance explained), but less so when both depression and LEE-irritability were high ('high mediators', $1 \%$ variance explained) and both depression and LEEirritability were low ('low mediators', $0.3 \%$ variance explained). Independently, depression had a significant indirect effect on positive schizotypy, because the upper and lower limits of the $95 \%$ confidence intervals (C.I.s) had a positive value. LEE-irritability did not have an indirect effect on positive schizotypy. The overall model explained $19 \%$ of the variance in relevance of criticism.

The second mediation analysis revealed that the personal relevance of praise had a significant total effect on cognitive disorganisation (Table 2). After including the mediators (LEEintrusiveness and positive mood), the direct effect of the personal relevance of praise on cognitive disorganisation was non-significant. Fig. 2 shows that the relation between the personal relevance of praise and cognitive disorganisation was stronger when LEEintrusiveness was high ('high mediators', 7\% variance explained), but positive mood was low, rather than when LEE-intrusiveness was low, but positive mood was high ('low mediators', $3 \%$ variance explained). Independently, neither LEE-intrusiveness nor positive mood had indirect effects on the relationship between personal relevance of praise and cognitive disorganisation. The overall model explained $31 \%$ of the variance in personal relevance of praise.

\section{Discussion}

High EE is a part of the stress diathesis of schizophrenia. This study tested the differences in the affective response to standard criticism and standard praise, and the relation of schizotypy to perceived criticism and perceived praise in the non-clinical population. Participants differentiated between the comments, such that praise was more arousing and relevant than criticism, which in turn was more arousing and relevant than neutral comments. The findings suggest that in a non-clinical sample, people have a preference for praise over criticism. In many affective paradigms, healthy participants show a preference for positive emotional stimuli [44]. As hypothesised, the greater personal relevance of criticism related to greater positive schizotypy and the lesser personal relevance of praise related to greater cognitive disorganisation. These findings are discussed below.

\subsection{Relationship between perceived criticism and schizotypy}

Perceived criticism related to all schizotypy subscales, namely positive schizotypy, cognitive disorganisation, and introvertive anhedonia, which supports evidence that EE-criticism relates to a vulnerability for psychosis [3] and that people at risk for psychosis find standard criticism more relevant than low-risk controls [45]. Young adults feel more paranoid after reading criticism, than warm or neutral statements [46]. Together, the findings suggest that greater criticism is perceived within the normal to sub-clinical range of the psychosis continuum, and its relation to schizotypy is multidimensional, meaning that it can follow both cognitive and affective pathways to psychosis-like experiences. These findings support the stress-diathesis model of schizophrenia [31] and evidence for the affective pathway to positive symptoms of psychosis, as suggested by Garety et al. [47]. However, the findings contradict evidence that social anxiety does not relate to psychotic symptoms, such as auditory hallunications and persecutory delusions [48]. Auditory hallucinations constitute the positive dimension of psychosis-like experiences, and often reflect a close relative's remarks, such as criticism [49]. Hallucinations and delusions could be more intense when criticism is perceived and when family conflict occurs. For instance, people with social anxiety internalise more criticism than people without social anxiety [9,50]. Adolescents at risk of developing psychosis can reciprocate such family conflict $[23,51]$, and so experience social threat. Depression and perceived irritability from a close relative fully mediated the relationship between the personal relevance of criticism and positive schizotypy, with depression mostly explaining this relationship. As posited by Garety et al. [47], affect might be

Table 2

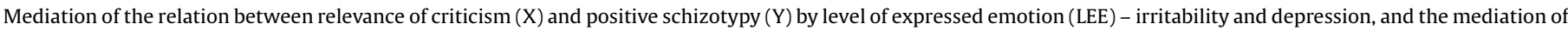
the relation between relevance of praise $(\mathrm{X})$ and cognitive disorganisation (Y) by level of expressed emotion (LEE) - intrusiveness and positive mood.

\begin{tabular}{|c|c|c|c|c|c|c|}
\hline Mediators & $\mathrm{a}_{\mathrm{n}}$ & $\mathrm{b}_{\mathrm{n}}$ & Indirect effect, $a_{n} \times b_{n}(95 \%$ C.I.) & Total effect $(\mathrm{c})$ & Direct effect (c') & Total $\mathrm{R}^{2}$ \\
\hline \multicolumn{7}{|c|}{ Relation between relevance of criticism $(\mathrm{X})$ and positive schizotypy $(\mathrm{Y})$} \\
\hline LEE-irritability & $0.426^{* *}$ & 0.258 & $0.110(-0.031$ to 0.318$)$ & $0.689 * *$ & 0.247 & 0.191 \\
\hline Depression & $1.380^{* * *}$ & $0.240^{* * *}$ & $0.331(0.089$ to 0.640$)$ & & & \\
\hline \multicolumn{7}{|c|}{ Relation between relevance of praise $(\mathrm{X})$ and cognitive disorganisation $(\mathrm{Y})$} \\
\hline LEE-intrusiveness & $-0.517^{*}$ & $0.238^{*}$ & $-0.123(-0.402$ to 0.016$)$ & $-0.719^{* *}$ & -0.457 & 0.317 \\
\hline Positive mood & $1.929^{* * *}$ & $-0.072^{* * *}$ & $-0.138(-0.453$ to 0.173$)$ & & & \\
\hline
\end{tabular}

Footnote: The correlation is significant at ${ }^{*} \mathrm{p} \leq 0.05$, ${ }^{* *} \mathrm{p} \leq 0.01$, and ${ }^{* * *} \mathrm{p} \leq 0.001$; LEE: Level of Expressed Emotion. 


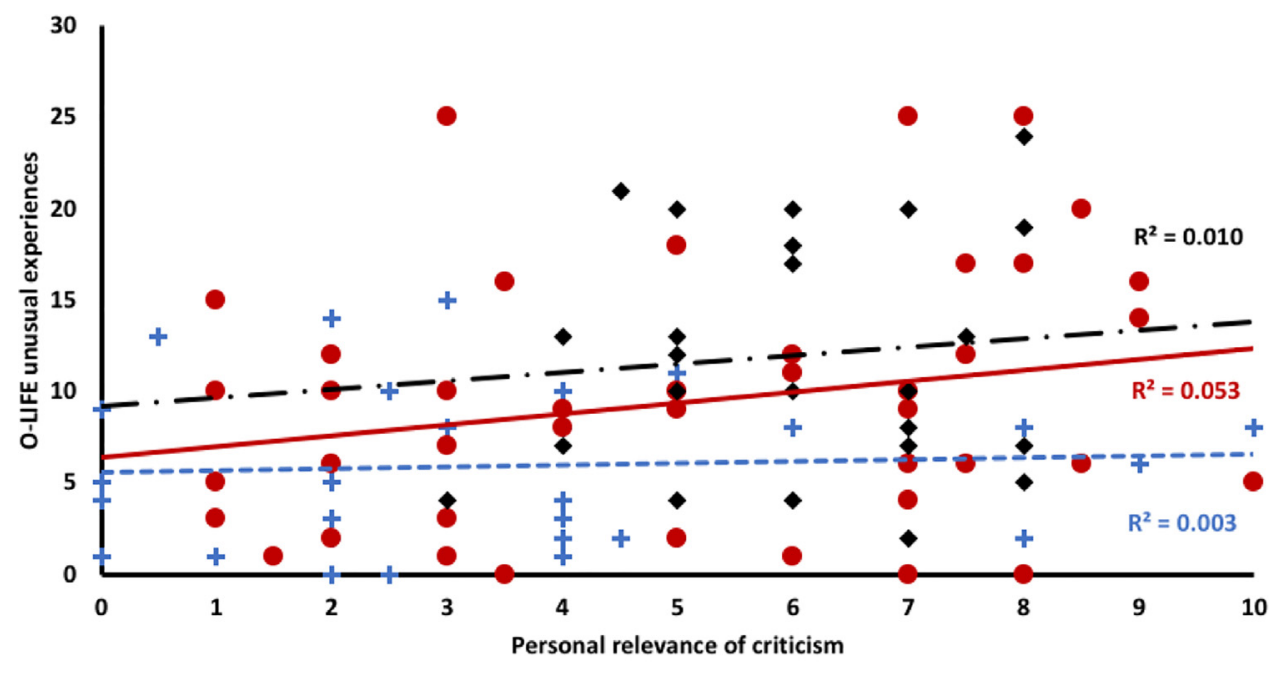

+ Low depression AND low perceived EE-irritability High depression OR high perceived EE-irritability

- High depression AND high perceived EE-irritability

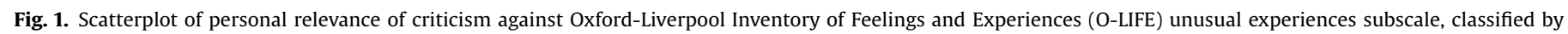

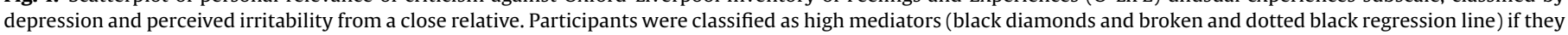

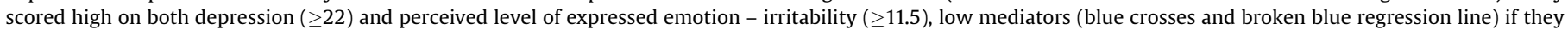

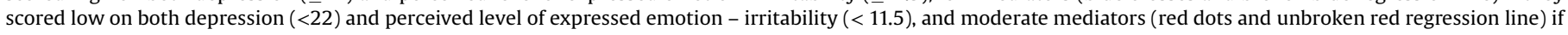

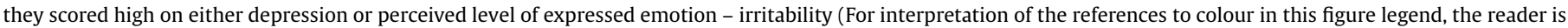
referred to the web version of this article.).

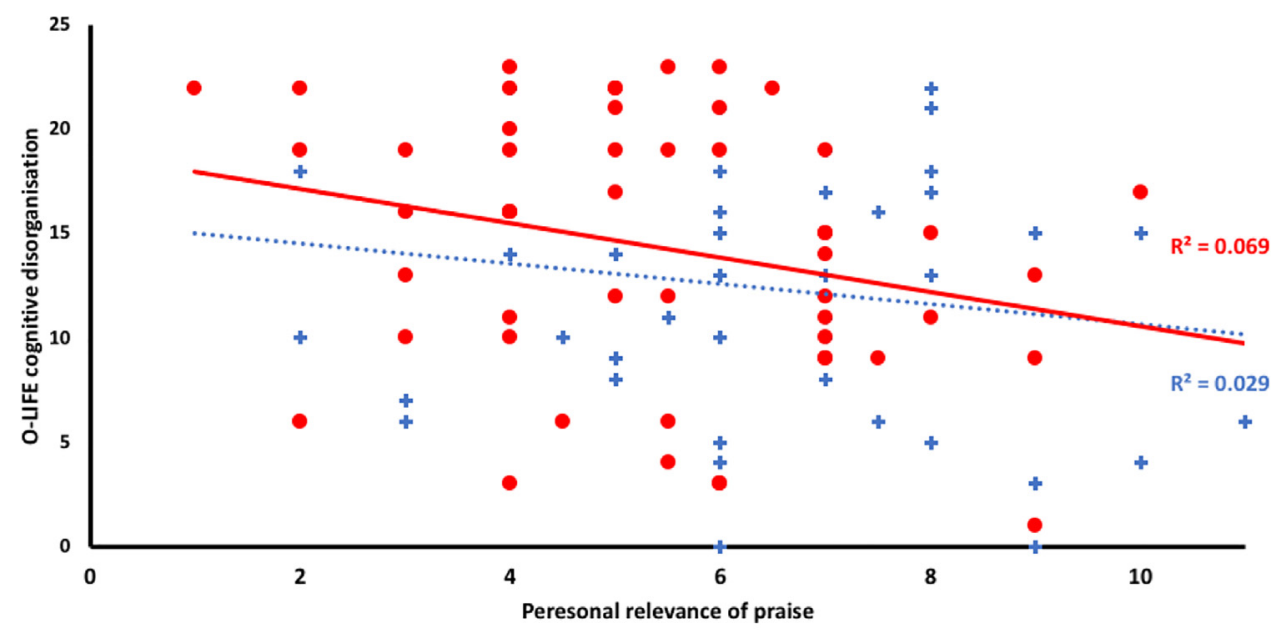

+ Low perceived EE-intrusiveness AND high positive mood - High perceived EE-intrusiveness OR low positive mood

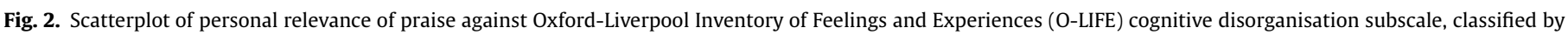

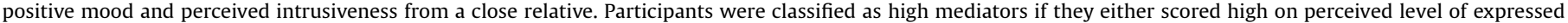

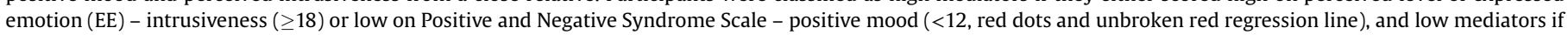

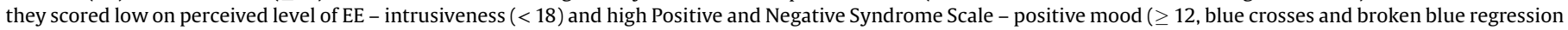
line) (For interpretation of the references to colour in this figure legend, the reader is referred to the web version of this article.).

the pathway to psychosis, as depression could denote having catastrophic thoughts about the threat posed by criticism. Such negative metacognitive beliefs are detrimental, and increase psychosis-like experiences $[13,14]$.

\subsection{Relationship between perceived praise and cognitive disorganization}

The study found a relationship between the lower personal relevance of praise and greater cognitive disorganisation in schizotypy. Praise denotes affection, approval, and the need to establish closeness [52]. Maternal praise could boost the child's feelings of competence and confidence [16]. Patients with schizophrenia can have symptoms of disorganisation if they do not perceive warmth and compassion for themselves [18]; therefore, they may not perceive praise from others. Warmth reduces the likelihood of subsequent relapse in patients with a recent onset of psychosis [53]. Praise from a close relative reduces disorganisation in adolescents at risk for psychosis [23].

Perceived EE-intrusiveness and positive mood partially mediated the relationship between the personal relevance of praise and cognitive disorganisation. When one is excessively praised by a relative, one could perceive the relative as trying to exert control over them, and not be interested in the praise. EOI, as denoted by perceived EE-intrusiveness, could limit the individual's autonomy and ability to perceive praise [27], instead making them feel 
anxious and disorganised [54]. Intrusive parenting can be manipulative through use of strategies of guilt-induction, love withdrawal, and conditional approval [55], which might well impede the ability to perceive praise. Positive mood could buffer the relationship between perceived praise and cognitive disorganisation. Praise enhances positive mood in people at risk for psychosis [45]. Positive mood enhances social connectedness, and satisfaction with family relationships [56,57], which can lower cognitive disorganisation. Having a positive mood when pursuing pleasurable activities relates to better emotional adjustment [58], which may lower cognitive disorganisation.

\subsection{Limitations and implications}

The study had a few limitations. The study's sample mainly consisted of University students (90\%) who were single and female. The findings may not generalise to older adults, couples, or people in non-academic settings. However, the use of psychology students in schizotypy research is not thought to adversely affect the validity of findings [59]. Yet, the participants' current or previous diagnosis of psychiatric disorder was not known in this study. Thus, the findings may not be exclusive to non-clinical schizotypal traits. Future research might address the role of other demographic characteristics relevant to the participant's family background, such as housing and type of family, in the relation between perceived EE and schizotypy.

The practical implications of the study are that the evaluation of standard criticism and standard praise could be used to assess the level of distress in patients with psychosis. This kind of research might also provide a theoretical basis for family intervention. Perceived EE has long-term effects on the cognition and affect of adolescents [15]. Parents of anxious young adults could be supported to modify their style of communication, i.e. speaking without excessive criticism or praise, as this would reduce the young adult's disorganisation. Early intervention services try to help families to improve their communication through problemsolving, sharing new ideas, and reassurance of worth [60,61], as well as helping individuals to achieve independence, appraising criticism constructively, and engaging in pleasurable social activities to increase positive mood and perceived praise [29].

\section{Conclusion}

Schizotypy relates to greater perceived criticism and praise in the healthy population due to affect and perceived irritability and intrusiveness from a close relative. These associations, if they persist, may increase the risk for psychosis. The evaluation of criticism and praise underline the ways in which the family can intervene to reduce distress. Such family intervention is recommended for those with psychosis [62,63].

\section{Declaration of conflict of interest}

The authors declare no conflict of interest.

\section{Statement of funding}

The authors received no funding from an external source.

\section{References}

[1] Leff J., Vaughn CE. The expressed emotion scales. In: Leff J, Vaughn CE, editors. Expressed emotion in families: its significance for mental illness. London: Guidlford Press; 1985. p. 37-63.

[2] Bebbington P, Kuipers L. The predictive utility of expressed emotion in schizophrenia: an aggregate analysis. Psychol Med 1994;24(August (3)):707-18.
[3] Schlosser DA, Zinberg JL, Loewy RL, Casey-Cannon S, O’Brien MP, Bearden CE, et al. Predicting the longitudinal effects of the family environment on prodromal symptoms and functioning in patients at-risk for psychosis. Schizophr Res 2010:118:69-75.

[4] Premkumar P, Williams SC, Lythgoe D, Andrew C, Kuipers E, Kumari V. Neural processing of criticism and positive comments from relatives in individuals with schizotypal personality traits. World J Biol Psychiatry 2013;14:57-70.

[5] Fonseca-Pedrero E, Debbané M, Ortuño-Sierra J, Chan RCK, Cicero DC, Zhang LC, et al. The structure of schizotypal personality traits: a cross-national study. Psychol Med 2018;48:451-62.

[6] Mason O, Claridge G, Jackson M. New scales for the assessment of schizotypy. Pers Individ Dif 1995;18:7-13.

[7] Beck A. A cognitive model of schizophrenia. J Cogn Psychother 2004;18:281-8.

[8] Morrison AP, Haddock G, Tarrier N. Intrusive thoughts and auditory hallucinations: A cognitive approach. Behav Cogn Psychother 1995;23:265-80.

[9] Porter E, Chambless DL, Keefe JR. Criticism in the romantic relationships of individuals with social anxiety. Behav Ther 2017;48(4):517-32.

[10] Day S, Peters E. The incidence of schizotypy in new religious movements. Pers Individ Dif 1999;27:55-67.

[11] van Rossum I, Dominguez M, Lieb R, Wittchen H, Van Os J. Affective dysregulation and reality distortion: a 10-year prospective study of their association and clinical relevance. Schizophr Bull 2011;37(3):561-71.

[12] Lewandowski K, Barrantes-Vidal N, Nelson-Gray R, Clancy C, Kepley H, Kwapil T. Anxiety and depression symptoms in psychometrically identified schizotypy. Schizophr Res 2006:83:225-35.

[13] Debbané M, Van der Linden M, Gex-Fabry M, Eliez S. Cognitive and emotional associations to positive schizotypy during adolescence. J Child Psychol Psychiatry 2009;50:326-34.

[14] Nordahl H, Nordahl HM, Vogel PA, Wells A. Explaining depression symptoms in patients with social anxiety disorder: do maladaptive metacognitive beliefs play a role? Clin Psychol Psychother 2018;1-8.

[15] Hale W, Raaijmakers W, Hoof $\mathrm{Q}$, Meeus A. The predictive capacity of perceived expressed emotion as a dynamic entity of adolescents from the general community. Soc Psychiatry Psychiatr Epidemiol 2011;46:507-15.

[16] Swenson S, Ho GW, Budhathoki C, Belcher HM, Tucker S, Miller K, et al. Parents' use of praise and criticism in a sample of young children seeking mental health services. J Pediatr Health Care 2016;30:49-56.

[17] van' T Wout M, Sanfey AG. Interactive decision-making in people with schizotypal traits: A game theory approach. Psychiatry Res 2011:185:92-6.

[18] Gumley A, Macbeth A. A pilot study exploring compassion in narratives of individuals with psychosis: implications for an attachment-based understanding of recovery. Ment Health Relig Cult 2014;1-18.

[19] Grant P, Beck A. Evaluation sensitivity as a moderator of communication disorder in schizophrenia. Psychol Med 2009;39:1211-9.

[20] Tompson MC, Asarnow JR, Hamilton EB, Newell LE, Goldstein MJ. Children with schizophrenia-spectrum disorders: thought disorder and communication problems in a family interactional context. J Child Psychol Psychiatry 1997;38:421-9.

[21] Coleman MJ, Levy DL, Lenzenweger MF, Holzman PS. Thought disorder perceptual aberrations, and schizotypy. J Abnorm Psychol 1996;105:469-73.

[22] Loas G, Dimassi H, Monestes J, Yon V. Criterion validity of the cognitive slippage and schizotypal ambivalence scales. Psychol Rep 2013;(113):930-4

[23] O’Brien M, Zinberg JL, Ho L, Rudd A, Kopelowicz A, Daley M, et al. Family problem solving interactions and 6-month symptomatic and functional outcomes in youth at ultra-high risk for psychosis and with recent onset psychotic symptoms: a longitudinal study. Schizophr Res 2009;107:198-205.

[24] Butzlaff RL, Hooley JM. Expressed emotion and psychiatric relapse: a metaanalysis. Arch Gen Psychiatry 1988;55:547-52.

[25] Domínguez-Martínez T, Medina-Pradas C, Kwapil T, Barrantes-Vidal N. Relatives' expressed emotion, distress and attributions in clinical high-risk and recent onset of psychosis. Psychiatry Res 2017;247:323-9.

[26] Kuipers E, Bebbington P, Dunn G, Fowler D, Freeman D, Watson P, et al. Influence of carer expressed emotion and affect on relapse in non-affective psychosis. Br J Psychiatry 2006;188:173-9.

[27] Gurland S, Grolnick T. Perceived threat, controlling parenting, and children's achievement orientations. Motiv Emotion 2005;29:103-21.

[28] Thorberg FA, Young RM, Sullivan KA, Lyvers M. Parental bonding and alexithymia: a meta-analysis. Eur Psychiatry 2011;26:187-93.

[29] Fredrickson B, Branigan C. Positive emotions broaden the scope of attention and thought-action repertoires. CognEmotion 2005;19:313-32.

[30] Cuellar A, Johnson S. Depressive symptoms and affective reactivity to maternal praise and criticism. J Soc Clin Psychol 2009;28:1173-94.

[31] Nuechterlein KH, Dawson ME. A heuristic Vulnerability/Stress model of schizophrenic episodes. Schizophr Bull 1984:10:300-12.

[32] Mason O. The assessment of schizotypy and its clinical relevance. Schizophr Bull 2015;41:S374-85.

[33] Lovibond SH, Lovibond PF. Manual for the depression, anxiety and stress scales. 2nd ed. Sydney: Psychology Foundation; 1995.

[34] Cole JD, Kazarian SS. The level of expressed emotion scale: a new measure of expressed emotion. J Clin Psychol 1988;44:392-7.

[35] Gerlsma C, Hale WW. Predictive power and construct validity of the level of expressed emotion (LEE) scale. Depressed out-patients and couples from the general community. Br J Psychiatry 1997;170:520-5.

[36] Hooley JM, Teasdale JD. Predictors of relapse in unipolar depressives: expressed emotion, marital distress, and perceived criticism. J Abnorm Psychol 1989;98:229-35. 
[37] Docherty N, St-Hilaire A, Aakre J, Seghers J, McCleery A, Divilbiss M. Anxiety interacts with expressed emotion criticism in the prediction of psychotic symptom exacerbation. Schizophr Bull 2011;37:611-8.

[38] Onwumere J, Kuipers E, Bebbington P, Dunn G, Freeman D, Fowler D, et al. Patient perceptions of caregiver criticism in psychosis: links with patient and caregiver functioning. J Nerv Ment Dis 2009;197(2):85-91.

[39] Watson D, Clark LA, Tellegen A. Development and validation of brief measures of positive and negative affect: The PANAS scales. J Pers Soc Psychol 1988;54:1063-70.

[40] Premkumar P, Dunn A, Kumari V, Onwumere J, Kuipers E. A Behavioural Task to Measure Appraisal of Standard Criticism and Standard Praise. Personal communication.

[41] Mathôt S, Schreij D, Theeuwes J. OpenSesame: an open-source, graphical experiment builder for the social sciences. Behav Res Methods 2012;44 (2):314-24.

[42] Hayes AF. Introduction to mediation, moderation, and conditional process analysis. 2nd ed. London: Guildford Press; 2018.

[43] Mason O, Claridge G, Jackson M. New scales for the assessment of schizotypy. Pers Individ Dif 1995;18:7-13.

[44] Clark MS, Milberg S, Erber R. Effects of arousal on judgments of others' emotions. J Pers Soc Psychol 1984;46(3):551-60.

[45] Weintraub MJ, de Mamani AW, Villano WJ, Evans TC, Millman ZB, Hooley JM, Timpano KR. Affective and physiological reactivity to emotional comments in individuals at elevated risk for psychosis. Schizophr Res. In press.

[46] Butler R, Berry K, Ellett L, Bucci S. An experimental investigation of the impact of critical and warm comments on state paranoia in a non-clinical sample. J Behav Ther Exp Psychiatry 2019;62:30-7.

[47] Garety PA, Kuipers E, Fowler D, Freeman D, Bebbington PE. A cognitive model of the positive symptoms of psychosis. Psychol Med 2001;31:189-95.

[48] Michail M, Birchwood M. Social anxiety disorder in first-episode psychosis: incidence, phenomenology and relationship with paranoia. Br J Psychiatry 2009; 195:234-41.

[49] Hayward M, Fuller E. Relating therapy for people who hear voices: perspectives from clients, family members, referrers and therapists. Clin Psychol Psychother 2010;17:636.

[50] Vriends N, Meral Y, Bargas-Avila JA, Stadler C, Bögels SM. How do I look? Selffocused attention during a video chat of women with social anxiety (disorder). Behav Res Ther 2017;92:77-86.
[51] Goldstein MJ, Miklowitz DJ, Strachan AM, Dozne JA, Nuechterlein KH, Feingold D. Patterns of expressed emotion and patient coping styles that characterise the families of recent onset schizophrenics. Br J Psychiatry 1989;155:107-11.

[52] Myers S, Byrnes K, Firsby B, Mansson D. Adult siblings' use of affectionate communication as a strategic and routine relational maintenance behavior. Commun Res Rep 2011;28:151-8.

[53] Lee G, Barrowclough C, Lobban F. Positive affect in the family environment protects against relapse in first-episode psychosis. Soc Psychiatry Psychiatr Epidemiol 2014;49:367-76.

[54] Jacobsen T, Hibbs E, Ziegenhain U. Maternal expressed emotion related to attachment disorganization in early childhood: a preliminary. J Child Psychol Psychiatry 2000;41:899-906.

[55] Barber BK. Parental psychological control: revisiting a neglected construct. Child Dev 2014;67:3296-319.

[56] Ramsey MA, Gentzler AL. An upward spiral: bidirectional associations between positive affect and positive aspects of close relationships across the life span. Dev Rev 2015;36:58-104.

[57] Smillie L, Wilt J, Kabbani R, Garratt C, Revelle W. Quality of social experience explains the relation between extraversion and positive affect. Emotion 2015;15:339-49.

[58] Gentler AL, Morey JN, Palmer CA, Yi CY. Young adolescents' responses to positive events: associations with positive affect and adjustment. J Early Adolesc 2013;33:663-83.

[59] Kwapil TR, Barrantes-Vidal N, Silvia PJ. The dimensional structure of the Wisconsin Schizotypy scales: factor identification and construct validity. Schizophr Bull 2008;34(3):444-57.

[60] Barnes H, Olson DH. Parent-adolescent communication. In: Olson DH, McCubbin HI, Barnes H, Larsen A, Muxen M, Wilson M, editors. Family inventories: inventories used in a national survey of families across the family life cycle. St. Paul MN: University of Minnesota; 1992.

[61] Cutrona C. A psychological perspective: marriage and the social provisions of relationships. J Marriage Fam 2004;66:992-9.

[62] National Institute of Health and Clinical Excellence. Psychosis and schizophrenia in adults (update) CG178. London: National Institute of Health and Clinical Excellence; 2014.

[63] Kuipers E, Yesufu-Udechuku A, Taylor C, Kendall T. Management of psychosis and schizophrenia in adults: summary of updated NICE guidance. Br Med J 2014;348:G1173. 